\title{
Memantine for prophylaxis of episodic migraine: a systematic review and meta-analysis
}

Mark Willy Llapitan Mondia ( $\square$ markwillymondia@gmail.com )

Philippine General Hospital https://orcid.org/0000-0001-8862-5360

Adrian Espiritu

Philippine General Hospital

Martha Lu Bolaños

Philippine General Hospital

Artemio, Jr. A. Roxas

Philippine General Hospital

\section{Research article}

Keywords: Memantine, NMDA antagonist, Episodic migraine, Prophylaxis, Systematic Review, Metaanalysis

Posted Date: February 17th, 2020

DOI: https://doi.org/10.21203/rs.2.23772/v1

License: (c) (i) This work is licensed under a Creative Commons Attribution 4.0 International License. Read Full License 


\section{Abstract}

Background Migraine is a common debilitating primary headache. Memantine is a non-competitive Nmethyl D-aspartate (NMDA) antagonist that lowers neuronal excitability that could prevent migraine attacks.

Objectives This study aimed to determine the efficacy and safety of memantine in patients experiencing episodic migraine attacks using a systematic review and meta-analysis.

Methods We searched CENTRAL, MEDLINE, Scopus, Cochrane, LILACS, ClinicalTrials.gov, HERDIN and Google Scholar for relevant studies. Prespecified screening and eligibility criteria for inclusion were applied. Included studies underwent methodological quality assessment. Study design, patient characteristics, interventions given, and relevant outcomes were extracted and synthesized.

Results This review included five relevant articles -2 randomized controlled trials (RCT) and 3 observational studies ( 1 retrospective case-series, 2 prospective non-randomized open-label single arm trials). There were 109 patients included in the RCTs and 197 patients reported in the observational studies. Pooled data from the 2 RCTs showed that Memantine at $10 \mathrm{mg} /$ day decreased the monthly migraine days at 12 weeks compared to placebo with a mean difference of -1.58 [ $95 \%$ confidence interval (Cl) $-1.84,-1.32]$. Observational studies also showed a decrease in migraine days per month with Memantine (5-20mg/day) after 12 weeks [95\% Cl]: -9.1 [-11, -7.23], -7.2 [-8.85, -5.55], and -4.9 [-6.29, -3.51]. There were no statistically significant adverse drug events (ADE) noted in patients treated with Memantine compared to placebo.

Conclusion Memantine may be effective and well-tolerated as prophylaxis for episodic migraine.

\section{Introduction}

Migraine is a primary headache that is usually unilateral, throbbing, and can be associated with nausea, vomiting, and photophobia [1, 2]. It has a global prevalence of $14.7 \%$ [3]. According to the latest study in 2016, migraine was estimated to have caused $\$ 45.1$ million-years lived with disability (YLD), which is a $51.2 \%$ increase since 1990. [4].

Post-synaptic neuronal activation of N-methyl D-aspartate (NMDA) by glutaminergic transmission is well established in its involvement with mechanisms related with initiation, propagation, and chronification of migraine attacks $[5,6]$. Memantine is a voltage-dependent, non-competitive antagonist of the NMDA receptor that decreases glutaminergic activity, thus possibly preventing migraine attacks [6] [7].

Memantine offers key advantages over other drugs for migraine prophylaxis. First, it has minimal side effects that are more tolerable [7]. Second, the time required for titration to therapeutic levels is shorter [7]. Third, it has a Pregnancy Safety Category B, thus is relatively safe to use in pregnancy [8]. Lastly, it is more accessible versus novel antibodies approved for prevention of episodic migraine. 
To the authors' knowledge, consolidated data on studies looking into Memantine for preventing acute migraine attacks is lacking. Therefore, the aim of this study was to determine the efficacy and safety of Memantine in patients with episodic migraine using systematic review and meta-analysis assessing for the following parameters - number of migraine days, headache intensity, quality of life, and adverse drug events (ADEs) [9].

\section{Methods}

This study adhered to the Meta-analysis of Observational Studies in Epidemiology (MOOSE) and Preferred Reporting Items for Systematic reviews and Meta-analyses (PRISMA) Guidelines [10] [11].

\subsection{Criteria for the selection of studies}

We considered randomized controlled trials (RCTs); prospective/retrospective cohort studies; and case series and reports. We included studies that involved patients 18 years old and above who were clinically diagnosed with episodic migraine (having less than 15 migraine days per month) according to the International Headache Society's (IHS) International Classification of Headache Disorders (ICHD- II or III) and previous versions [12] [2]. Studies that enrolled patients who received migraine prophylaxis in the past 3 months as well as those diagnosed of chronic migraine and/or medication-overuse headache $(\mathrm{MOH})$ were excluded. We considered studies that employed Memantine alone or in combination with other prophylactic drugs regardless of drug dosage and duration of treatment

\subsection{Primary and secondary outcomes}

The primary outcome for this review was headache frequency measured as mean number of migraine days per month. To determine treatment effect, the mean difference was computed between mean migraine days per month at a particular time period of exposure to treatment and baseline.

Secondary outcomes included: 1) intensity of headaches measured via pain Numerical Rating Score (NRS), which is a scale from 0 (no pain) to 10 (most severe pain) and Head Impact Test (HIT) that ranges from 36 to 78 with higher scores indicating increase in severity of pain, 2) adverse drug events, and 3) Migraine Disability Assessment Scale (MIDAS), which is a 5-item tool that measures migraine-related disability and functional consequences where a higher score corresponds to more severe disability; Hospital Anxiety and Depression Scale (HADS), which is a 14-item questionnaire that assesses mood status on a 4-point scale wherein a higher score means higher level of anxiety and depression; Pittsburgh sleep quality index (PSQI), which is a 19-item questionnaire to assess sleep quality with higher scores indicating poorer sleep; and Short-form 12 (SF), which is a 12-item tool for mental and physical healthrelated quality of life [9].

\subsection{Search methods for identification of studies}

Literature search using medical subject headings (MeSH) and free texts related to ("migraine") and ("Memantine") were used. The following databases were systematically searched from January 2019 to 
July 2019: Medline (PubMed), Central Register of Controlled Trials (CENTRAL), ClinicalTrials.gov website, Scopus, Literatura Latino-Americana e do Caribe em Ciências da Saúde (LILACS), and Health Research and Development Information Network (HERDIN) of the Philippines, and Google Scholar. The reference lists of selected studies were also searched for relevant studies.

Titles and abstracts of studies were screened according to the set criteria. Full-text articles were obtained for relevant studies and were reviewed based on the eligibility criteria to determine inclusion in this review. Included studies were then subjected to qualitative and quantitative analyses.

\subsection{Risk bias assessment, data collection and analysis}

Risk of bias was assessed for each included study. The Cochrane Collaboration Tool was used for RCTs. For case reports/series, the tool developed by Murad [13] was used to assess for bias. This tool combined eight items that were categorized into four domains: selection, ascertainment, causality, and reporting. More than the numerical aggregate score representation of the binary choices, an overall judgement about methodological quality should be based on the questions deemed most critical in the specific clinical scenario [13]. For this review's clinical query, questions on selection, ascertainment, and follow-up are most important to determine risk of bias.

Year publication, study design, population size and baseline characteristics, dose and titration rate of Memantine, duration of treatment, follow-up, number of migraine days, intensity of headaches, measures for depression, cognitive performance, well-being, and quality of life, withdrawals, and adverse drug events were extracted from each included study.

For continuous outcomes, mean differences (MD) with $95 \% \mathrm{Cl}$ were employed as measure of treatment effect. For dichotomous outcomes, risk ratios (RR) with $95 \% \mathrm{Cl}$ were used. Data were synthesized using the Review Manage (RevMan) 5.3 (Copenhagen: The Nordic Cochrane Centre, The Cochrane Collaboration, 2014). We pooled continuous outcomes using the inverse-variance method and dichotomous outcomes using the Mantel-Haenszel method. Meta-analysis was performed using the fixed-effects model. For continuous outcomes, statistically significant difference between the intervention and control groups were noted if the $95 \% \mathrm{Cl}$ of the mean difference (MD) did not include the number 0 . For dichotomous outcomes, statistical significance was detected if the $95 \%$ of the RR did not include the number 1 . Statistical heterogeneity was measured using the $I^{2}$ statistic with values 0 to $40 \%$ indicating unimportant heterogeneity

\section{Results}

\subsection{Included studies}

As shown in Fig. 1, identification, screening, and application eligibility criteria to relevant studies were done. Eight databases were searched, which generated a total of 698 records (PubMed: 24; Cochrane: 7; Google scholar: 105; review of references: 7; Scopus: 555; ClinicalTrials.gov, controlled-trials.com, LILACS, 
HERDIN: 0). Fifteen duplicates were removed. Screening of titles and abstracts was done for 683 reports from which 676 records were excluded. Full-text articles for 7 studies were obtained and evaluated for eligibility. Two studies were excluded since they were review articles. Five studies fulfilled the inclusion criteria. The two randomized controlled trials were analyzed for meta-analysis.

\subsection{Study design and patient population}

Five studies satisfied the inclusion criteria. All these studies were published in peer-reviewed journals - 3 of which in international journals (Charles 2007 [14]; Bigal 2008 [6]; Noruzzadeh 2015 [7]), one local journal in Iran (Assarzadegan 2017 [15]), and one local journal in India (Shanmugam 2019 [16]). Shown in Table 1 are the patient characteristics and methodology used.

These studies were of different designs - 2 randomized controlled trials, 2 prospective non-randomized open-label single arm trials, and 1 retrospective case-series. All studies based diagnosis of migraine according to the ICDH-II. A total of 317 patients were included -120 patients randomized for the two RCTs (30 patients in the Memantine arm and 30 patients in the placebo arm, per study) and 197 for the observational studies.

There was a predominance of female participants (female-to- male ratio of 3.13:1). Mean age ranged between 27 to 57 years old. Dosing of Memantine ranged from $5 \mathrm{mg} /$ day to $20 \mathrm{mg} /$ day depending on patient tolerance and satisfaction with pain control. Only the randomized trials used a pre-determined dose of $10 \mathrm{mg} /$ day. Three observational studies allowed inclusion of other preventive medication provided they had adequate and stable doses for more than 3 months. Both RCTs intended to eliminate the effect of other migraine preventive medications. Noruzzadeh 2015 excluded patients who received migraine prophylaxis in the past 3 months, while Shanmugam 2019 discontinued other preventive medication during the study period. Acute pain medication was allowed by these two RCTs.

Two RCTs were eligible for meta-analysis. They compared Memantine at a fixed dose of $10 \mathrm{mg} /$ day versus a placebo control. Each study randomized 60 patients into 30 patients allocated in the Memantine arm and 30 patients to the placebo arm.

Noruzzadeh 2015 limited their inclusion criteria to migraine with aura, while Shanmugam 2019 included all patients classified with migraine under the ICDH guidelines, but both studies were limited to episodic migraines.

Noruzzadeh 2015 had stricter exclusion criteria that did not consider patients who had medicationoveruse headaches, use of antipsychotics or antidepressants in the past 3 months, recent history of alcohol or drug abuse, allergy to Memantine, treatment-resistant migraine, pain disorder, severe psychiatric illness, severe infection, malignancy, low survival chance, severe cardiovascular disease, neurodegenerative disorders, pregnancy and lactation, and sexually active women. In comparison, Shanmugam 2019 excluded patients with headaches that did not respond to more than two migraine preventive medications, pregnant/breastfeeding women, medication-overuse headaches, severe medical illness, renal insufficiency, hepatic problems, and hypersensitivity. 
For the study of Noruzzadeh 2015, 2 were lost to follow-up and 3 discontinued intervention in the Memantine arm, while 3 discontinued in the placebo arm. As for Shanmugam 2019, 2 were lost to followup in the intervention arm and 1 lost to follow-up in the placebo arm.

Both studies looked into migraine days per month starting with a baseline measurement with Shanmugam 2019 having a longer baseline phase of 3 months versus a month for Noruzzadeh 2015. Shanmugam 2019 had more frequent data point gathering set at every 4 weeks for a longer follow-up of 24 weeks compared to the Noruzzadeh 2015, which only looked at migraine days per month at baseline and after 12 weeks.

\subsection{Methodological quality assessment}

Bias was evaluated using the Cochrane Collaboration's tool for the RCTs of Noruzzadeh 2015 and Shanmugam 2019. The trials were randomized with low risk for selection, performance, detection, attrition, and reporting bias indicating an excellent level of methodological quality as seen in Fig. 2 .

Table 1. Patient characteristics and methods used in included studies. 


\begin{tabular}{|c|c|c|c|c|c|c|c|}
\hline \multirow[t]{2}{*}{ Study } & \multirow[t]{2}{*}{ Design } & \multirow[t]{2}{*}{ Inclusion } & \multicolumn{4}{|c|}{ Population $(n=317)$} & \multirow{2}{*}{$\begin{array}{l}\text { Methods } \\
\text { Additional } \\
\text { Medication }\end{array}$} \\
\hline & & & Size & $\begin{array}{c}\text { Sex } \\
(\mathrm{F}: \mathrm{M}) \\
\end{array}$ & $\begin{array}{c}\text { Age } \\
\text { (Mean) }\end{array}$ & $\begin{array}{c}\text { Treatment } \\
\text { (Memantine) }\end{array}$ & \\
\hline $\begin{array}{l}\text { uzzadeh } \\
5\end{array}$ & $\begin{array}{l}\text { Randomized } \\
\text { placebo- } \\
\text { controlled } \\
\text { parallel group } \\
\text { trial }\end{array}$ & $\begin{array}{l}\text { ICHD-II diagnosis of } \\
\text { episodic migraine } \\
\text { specifically without aura }\end{array}$ & 30 & $\begin{array}{c}3.28: \\
1\end{array}$ & 34.8 & $\begin{array}{l}1 \text { month baseline } \\
\text { observation } \\
10 \mathrm{mg} / \text { day for } 12 \\
\text { weeks }\end{array}$ & $\begin{array}{l}\text { Excluded } \\
\text { patients who } \\
\text { received } \\
\text { migraine } \\
\text { prophylaxis } \\
\text { in the past } 3 \\
\text { months } \\
\text { Acute pain } \\
\text { medication } \\
\text { was allowed }\end{array}$ \\
\hline $\begin{array}{l}\text { nmugam } \\
9\end{array}$ & $\begin{array}{l}\text { Randomized, } \\
\text { double-blind, } \\
\text { placebo- } \\
\text { controlled } \\
\text { parallel trial at a } \\
\text { tertiary care } \\
\text { hospital in Tamil } \\
\text { Nadu }\end{array}$ & $\begin{array}{l}\text { ICHD-II diagnosis of } \\
\text { episodic migraine }\end{array}$ & 30 & $2: 1$ & 30 & $\begin{array}{l}3 \text { month baseline } \\
\text { phase } \\
10 \mathrm{mg} / \text { day for } 24 \\
\text { weeks }\end{array}$ & $\begin{array}{l}\text { Preventive } \\
\text { medication } \\
\text { was } \\
\text { discontinued } \\
\text { and only } \\
\text { allowed } 1 \\
\text { rescue } \\
\text { medication }\end{array}$ \\
\hline rles 2007 & $\begin{array}{l}\text { Retrospective } \\
\text { analysis of cases } \\
\text { using a survey } \\
\text { sent to patients }\end{array}$ & $\begin{array}{l}\text { ICHD-II diagnosis of } \\
\text { episodic migraine }\end{array}$ & 60 & $\begin{array}{c}4.45: \\
1\end{array}$ & 49 & $\begin{array}{l}\text { Initial } 5 \mathrm{mg} / \text { day } \\
\text { then increased by } \\
5 \mathrm{mg} / \text { week up to } \\
\text { 20mg/day } \\
\text { depending on } \\
\text { lowest dose with } \\
\text { satisfaction in pain } \\
\text { control } \\
1 \text { on } 5 \mathrm{mg}, 7 \text { on } \\
10 \mathrm{mg}, 1 \text { on } 15 \mathrm{mg}, 45 \\
\text { on } 20 \mathrm{mg}]\end{array}$ & $\begin{array}{l}\text { All patients } \\
\text { had previous } \\
\text { multiple } \\
\text { preventive } \\
\text { medication }\end{array}$ \\
\hline al 2008 & $\begin{array}{l}\text { Non-randomized } \\
\text { rospective open- } \\
\text { label single-arm } \\
\text { trial in a tertiary } \\
\text { hospital from } \\
2006-2007\end{array}$ & $\begin{array}{l}\text { ICHD-II diagnosis of } \\
\text { episodic migraine } \\
\text { including refractory } \\
\text { migraine (episodic } \\
\text { migraine with failure to } \\
\text { at least one preventive } \\
\text { medication) }\end{array}$ & 28 & $3: 1$ & 43.5 & $\begin{array}{l}1 \text { month baseline } \\
\text { observation } \\
\text { Initial } 10 \mathrm{mg} / \text { day (19 } \\
\text { patients, } 67.85 \% \text { ) } \\
\text { then after } 1 \text { month } \\
\text { of no side effects } \\
\text { and satisfactory } \\
\text { pain control, dose } \\
\text { was increased to } \\
20 \text { mg/day ( } 9 \\
\text { patients, } 32.1 \% \text { ) for } \\
3 \text { months }\end{array}$ & $\begin{array}{l}42.8 \% \text { used } \\
\text { one } \\
\text { preventive } \\
\text { drug } \\
51.8 \% \text { used } \\
2 \text { preventive } \\
\text { drugs }\end{array}$ \\
\hline $\begin{array}{l}\text { arzadegan } \\
7\end{array}$ & $\begin{array}{l}\text { Non-randomized } \\
\text { prospective open- } \\
\text { label single-arm } \\
\text { trial at Hossein } \\
\text { Hospital from } \\
2011-2013\end{array}$ & $\begin{array}{l}\text { ICHD-II diagnosis of } \\
\text { episodic migraine } \\
\text { including refractory } \\
\text { migraine (episodic } \\
\text { migraine with failure to } \\
\text { at least one preventive } \\
\text { medication) }\end{array}$ & 109 & $\begin{array}{c}3.42: \\
1\end{array}$ & 40 & $\begin{array}{l}1 \text { month baseline } \\
\text { observation } \\
\text { Initial } 5 \mathrm{mg} / \text { day, } \\
\text { then additional } 5 \mathrm{mg} \\
\text { every } 2 \text { weeks if no } \\
\text { side effects and } \\
\text { inadequate pain } \\
\text { control up to total of } \\
\text { 20mg/day for } 3 \\
\text { months }\end{array}$ & $\begin{array}{l}40.4 \% \text { used } \\
\text { one } \\
\text { preventive } \\
\text { drug } \\
\\
59.6 \% \text { used } \\
2 \text { or more } \\
\text { preventive } \\
\text { drugs }\end{array}$ \\
\hline
\end{tabular}


For the three included observational studies, bias was assessed using the tool proposed by Murad 2017 as seen in Table 2. All three observational studies had no comparators, thus alternative explanations for the noted effects could not be fully verified. There was also no challenge/re-challenge done in all studies. As for dose-response effect, the authors graded this to be "unclear" since maximum dose was determined by the dose at which patients were satisfied with pain control and no adverse effects were present. The remaining questions were satisfied by all three studies. Therefore, all observational studies satisfactorily addressed the necessary aspects for good methodological quality.

Table 2. Risk of bias assessment for included case reports and case series studies.

\begin{tabular}{|c|c|c|c|c|}
\hline Domains & Leading explanatory questions & $\begin{array}{l}\text { Assarzadegan } \\
2017\end{array}$ & $\begin{array}{l}\text { Bigal } \\
2008 \\
\end{array}$ & $\begin{array}{c}\text { Charles } \\
2007\end{array}$ \\
\hline Selection & $\begin{array}{l}\text { 1. Does/Do the patient(s) represent(s) the whole experience of the } \\
\text { investigator (centre) or is the selection method unclear to the } \\
\text { extent that other patients with similar presentation may not have } \\
\text { been presented? }\end{array}$ & $\begin{array}{l}\text { Clear } \\
\text { selection } \\
\text { method }\end{array}$ & $\begin{array}{l}\text { Clear } \\
\text { selection } \\
\text { method }\end{array}$ & $\begin{array}{l}\text { Clear } \\
\text { selection } \\
\text { method }\end{array}$ \\
\hline \multirow[t]{2}{*}{ Ascertainment } & 2. Was the exposure adequately ascertained? & Yes & Yes & Yes \\
\hline & 3. Was the outcome adequately ascertained? & Yes & Yes & Yes \\
\hline \multirow[t]{4}{*}{ Causality } & $\begin{array}{l}\text { 4. Were other alternative causes that may explain the observation } \\
\text { ruled out? }\end{array}$ & No & No & No \\
\hline & $\begin{array}{l}\text { 5. Was there a challenge/ } \\
\text { re-challenge phenomenon? }\end{array}$ & No & No & No \\
\hline & 6. Was there a dose-response effect? & Unclear & Unclear & Unclear \\
\hline & 7. Was follow-up long enough for outcomes to occur? & Yes & Yes & Yes \\
\hline Reporting & $\begin{array}{l}\text { 8. Is the case(s) described with sufficient details to allow other } \\
\text { investigators to replicate the research or to allow practioners to } \\
\text { make inferences to their own practice? }\end{array}$ & Yes & Yes & Yes \\
\hline
\end{tabular}

\subsection{Effects of the intervention}

Seen in Table 3 are the primary and secondary outcomes from included studies.

\subsubsection{Migraine days}

The main outcome for all studies focused on the mean difference for migraine days per month from baseline to 12 weeks follow-up.

Data used for meta-analysis is presented in Fig. 3. Note that combinable data was only available for the 12-weeks timepoint. Statistically significant decrease in monthly migraine days was only seen from 16 weeks onwards in the study of Shanmugam 2019. Combining both studies, as seen in 3.1.3 12 weeks inset of Fig. 3, the forest plot showed an overall treatment effect expressed as mean difference of 1.58 $[-1.84,-1.32]$ with $95 \% \mathrm{Cl}$. This translates to about a reduction of about 1.6 migraine days in a month at 12 weeks with Memantine (10 mg/day) versus placebo.

For the observational studies of Charles 2007, Bigal 2008, and Assarzadegan 2017, migraine days decreased compared to initial baseline with mean difference with $95 \% \mathrm{Cl}$ of $-9.1[-11,-7.23],-7.2[-8.85$, 
$-5.5]$, and $-4.9[-6.29,-3.51]$ respectively. Charles 2007 had no $p$ value stated, while Bigal 2008, and Assarzadegan 2017 both showed statistically significant $p$ values of $<0.01$ and 0.001 , respectively.

\subsubsection{Secondary outcomes}

MIDAS was available for one observational (Bigal 2008) and one RCT (Noruzzadeh 2015) with mean differences of $-20.7[-28.1,-13.3]$ and $-10.5[-12.2,-8.79]$, respectively; showing a decrease from baseline - with patients in the Bigal 2008 study to have higher baseline of severe disability, while patients in the Noruzzadeh starting from moderate disability, but both eventually decreasing to mild disability.

As for headache severity, the studies of Assarzadegan 2017 and Noruzzadeh 2015 used pain NRS, while the study of Bigal 2008 used HIT. In all three studies, the mean differences showed a decrease from baseline: -3 [-3.43 to -2.57] (Noruzzadeh 2015), -3.3 [-3.59 to -3.01] (Assarzadegan 2017), and - 17.2 [-23.6 to -10.8$]$ (Bigal 2008).

These values could not be combined due to a difference in study designs and pain scale used; nonetheless the values showed decrease in headache severity and migraine-related disability when Memantine was administered.

Additional secondary outcomes also favored the use of Memantine. Charles 2007 reported that patients who took Memantine had: 1 ) decreased headache severity; 2) reduced amount of medication taken; 3 ) improved level of function; and 4) $67 \%$ of patients had $50 \%$ reduction in monthly headaches. Bigal 2008 reported a decrease in number of days with severe pain with mean difference of $-4.5[-5.61,-3.39]$ with $95 \% \mathrm{Cl}$, while Shanmugam 2019 reported a decrease in the number of days wherein rescue medication was used with mean difference of -6.36 [-6.51, -6.21] with 95\% Cl. Lastly, Noruzzadeh 2015 reported: 1) decrease in migraine attacks per month with mean difference of $-3.5[-4.14,-2.86]$ with $95 \% \mathrm{Cl} ; 2$ ) decrease in number of days absent from work with mean difference of $-1.2[-1.63,-0.767]$ with $95 \% \mathrm{Cl} ; 3$ ) decrease in the number of acute pain medications used per episode with mean difference of $-1[-1.51$, -0.488 ] with $95 \% \mathrm{Cl}$; 4 ) better mental and physical health-related quality of life with increase in SF-12 score with mean difference of $1.1[-1.62,3.82]$ with $95 \% \mathrm{Cl}$ for mental component and mean difference of $1.9[0.15,3.65]$ with $95 \% \mathrm{Cl}$ for physical component; 5 ) less anxiety with lower HADS with mean difference of $-1.5[-2.63,-0.37]$ with $95 \% \mathrm{Cl} ; 6$ ) less depression with lower HADS with mean difference of $-1.3[-2.39,-0.21]$ with $95 \% \mathrm{Cl}$; and 7) decrease in PSQI indicating better with mean difference of -1.2 $[-2.12,-0.277]$ with $95 \% \mathrm{Cl}$.

ADEs noted in the RCTs were pooled with subgroup analysis per event and reported as risk ratio $(95 \% \mathrm{Cl})$ as seen in Fig. 4. None of the reported ADEs showed statistically significant risk ratios indicating a relatively good safety profile with the use of Memantine in included patients. Charles 2007 reported 2 patients with agitation, and one patient each who had a rash, cognitive dysfunction, and extremity pain. Bigal 2008 reported 7 patients who had somnolence, 3 patients with anxiety, 3 patients with asthenia, 3 patients who had weight gain, 2 who had depression, 2 had emotional instability, 1 had constipation, 1 with vertigo, and 1 with imbalance. 
Table 3. Pertinent results of included studies.

\begin{tabular}{lccc}
\hline Study & Monthly Migraine Days & MIDAS & Headache Severity \\
\cline { 2 - 4 } & $\begin{array}{c}\text { Mean Difference } \\
\text { [CI 95\%] }\end{array}$ & Mean Difference [CI 95\%] & Mean Difference [CI 95\%] \\
\hline Noruzzadeh 2015 & -7.0 & -10.5 & -3 \\
& {$[-7.73,-6.27]$} & ND & {$[-3.43,-2.57]$} \\
\hline Shanmugam 2019 & -5.61 & & ND \\
& {$[-5.73,-5.49]$} & ND & ND \\
\hline Charles 2007 & -9.1 & & $-17.79]$ \\
& {$[-11,-7.23]$} & -20.7 & {$[-23.6,-10.8]$} \\
\hline Bigal 2008 & -7.2 & ND & -3.3 \\
& {$[-8.85,-5.55]$} & -4.9 & {$[-3.59,-3.01]$} \\
\hline Assarzadegan 2017 & {$[-6.29,-3.51]$} & &
\end{tabular}

$\mathrm{ND}=$ no data

\section{Discussion}

This review systematically searched from 8 major journal and citation index databases and resulted to 2 randomized controlled trials and 3 observational studies. From the 317 total patients, 257 patients were exposed to Memantine, 60 of which were randomized; the rest were from the observational studies. In terms of efficacy, meta-analysis of two RCTs with 30 patients (3 dropouts in Noruzzadeh 2015 and 2 dropouts in Shanmugam 2019) in each treatment arm of Memantine at $10 \mathrm{mg} /$ day versus placebo resulted to an overall decrease of 1.58 migraine days per month compared to baseline at 12-weeks follow-up. Qualitative reporting of observational studies also showed that patients given Memantine had a statistically significant decrease of 3.51 to 11 migraine days per month after 12-weeks compared to baseline. In terms of safety, quantitative analysis of ADEs demonstrated no significant difference between Memantine and placebo. These data suggest that Memantine may be an effective and safe prophylactic drug for episodic migraine.

According to the Global Burden of Disease Study last 2010, migraine ranked third in prevalence worldwide as well as the third-highest cause of disability across both sexes under the age of 50 [2]. According to the American Association of Neurology (AAN) last 2012, around 38\% of migraineurs need preventive therapy, but only $3 \%-13 \%$ avail of preventive medication [17]. Prevention of migraine can lead to significant improvement in health-related quality of life.

In one recent review by Rau and Dodick 2008 [9], which incorporated guidelines from the American Association of Neurology (AAN), American Headache Society (AHS), and Canadian Headache Society (CHS), they listed alpha-adrenergic agonists, angiotensin-converting enzyme inhibitors (ACEls), angiotensin receptor blockers (ARBs), calcium channel blockers (CCBs), and serotonin antagonists as preventive migraine agents. Targeted therapy via monoclonal antibodies have also been used for migraine treatment. Last 2018, Erenumab, Fremanezumab, and Galcanezumab were approved for 
prophylaxis for episodic migraine. However, for most of these drugs, intolerable side effects and cost are the common detriment for patient compliance.

Memantine may be an ideal drug for migraine prophylaxis due to its pharmacokinetics. Additionally, Memantine has been widely used with a good safety profile in the treatment of Alzheimer's disease, wherein most of the elderly taking this drug have a variety of co-morbid diseases - proof of its tolerability with most patient populations [18]. Most experience with this drug for migraine were clinical data from observational studies, which all showed positive results suggesting the effectivity of Memantine in migraine prophylaxis. Based on latest guidelines, Memantine has only Level C (weak) evidence for the prophylaxis of migraine since until recently, there was only one published RCT that had favorable results for Memantine [8] [7]. With recent available RCT evidence that supports Memantine use, a stronger level of recommendation may be given to Memantine [16].

Study design inclusion criterion for this review was deliberately expanded to include observational studies to generate a more comprehensive database due to the paucity of currently published evidence. Episodic rather than chronic migraine was prioritized since most drugs for migraine prophylaxis would initially be evaluated for acute attacks prior to proceeding to a less common population of chronic migraineurs. Frequency of headaches expressed as migraine days in a month was the primary outcome measured. Since prevention of attacks is the primary concern, the duration of each attack would be less appropriate to analyze as this is more of a measure migraine attack termination. Based on these parameters, evidence gathered from this review is applicable to patients experiencing migraine attacks less than 15 migraine days in a month.

Risk of bias was relatively low for the two RCTs. All included observational studies adhered to a common reference for migraine diagnosis, provided a reproducible methodology, and presented the necessary data to evaluate the efficacy of Memantine for migraine prophylaxis - showing a good methodological quality.

There were significant observations identified regarding characteristics of the studies included in this review. First, clinical heterogeneity in terms of the populations enrolled in the RCTs may be remarkable. No sub-group distinction between migraine with and without aura was made. Although both migraine types are usually treated similarly, it has been suggested that response to treatment may be different for migraine sub-types due their distinct pathophysiology [19]. Stricter inclusion criteria that will ensure homogeneity will thus benefit future studies to determine if sub-analysis of pure migraineurs with and without aura will have an effect.

Second, data extrapolated from the small sample size of both RCTs may inherently cause imprecision of measured outcomes. A larger sample size may be used for future RCTs to generate stronger level of evidence.

Third, there were differences in doses used in the observational studies. The dose of $10 \mathrm{mg} / \mathrm{day}$ used in RCTs was based from the previous observational studies that determined this as the maximal dose 
wherein patients had satisfactory pain control with no adverse drug effects. Memantine dosing can go as high as $20 \mathrm{mg} /$ day, thus it would be judicious to explore the effects of an increased dose for Memantine in future migraine prophylaxis studies.

Fourth, though all studies considered a similar time point for follow-up, an extended duration of drug exposure can be explored as was done in Shanmugam 2019 especially since data from this study suggested that significant difference in headache frequency was only evident after 16 weeks.

Fifth, use of other preventive and rescue medication was not fully controlled in all included studies. For succeeding studies, it would be advantageous to examine patients with no previous exposure to any prophylactic medication.

Lastly, the more practical approach is to determine if the positive outcomes that were measured in the included studies actually clinically significant. Disability measures like MIDAS may help define more meaningful results that could translate to clinically applicable data [9]. Not all included studies reported quality of life outcomes, thus it is highly recommended to expand analysis to include these measures to determine if statistically significant results on reduction of migraine days translate to clinically significant data. Furthermore, clinical trials involving head-on comparison of Memantine versus other active prophylactic drugs in patients with episodic migraine may be beneficial to determine the relative place in therapy of Memantine in this condition.

Currently, this is the only comprehensive consolidated study to systematically review and pool available data to provide good quality evidence regarding the efficacy and safety of Memantine for episodic migraine prophylaxis. This review provides a moderate level of evidence for the efficacy of memantine for the prevention of episodic migraine based on the pooled data from the 2 relevant studies with low risk of bias but with relatively low sample size. The point estimates with its confidence intervals of the outcomes measured did not cross statistical clinical threshold to dissuade from the use of memantine.

Thus, additional well-designed randomized placebo-controlled trials with: 1) a larger and more homogenous population, 2) include dose-effect analysis, 3) head-on comparison with other active drugs,

and 4) measure more outcomes focused on disability and quality of life are recommended to validate the efficacy and safety of Memantine for patients with episodic migraine.

\section{Conclusion}

Our study showed that memantine has a beneficial effect on migraine prophylaxis compared to placebo as well as having a good tolerability profile based on pooled evidence from small clinical trials and single-arm observational studies. Memantine resulted to a decrease in migraine days per month and showed insignificant occurrence of adverse events. Further trials should have higher sample size and dose-response effect of memantine may be determined to substantiate the conclusions of this review. Effects of memantine on clinically significant outcome measures for patients with episodic migraine 
should be explored. Head-on comparison of memantine with other active drugs may be necessary to determine the place in therapy of memantine among the available prophylactic drugs for migraine.

\section{Declarations}

\subsection{Ethics approval and consent to participate}

Ethics approval and consent to participate is not applicable to our study.

\subsection{Consent for publication}

There were no personal data of any individual included in our study, hence consent for publication is not applicable.

\subsection{Availability of data and materials}

All data generated or analyzed during this study are included in this published article.

\subsection{Competing interests}

The authors declare that they have no competing interests.

\subsection{Funding}

This research did not receive any specific grant from funding agencies in the public, commercial, or notfor-profit sectors.

\subsection{Authors' contribution}

MWLM and AIE did the literature search, applied the inclusion and inclusion criteria, and gathered and analyzed pertinent data for the generation of the meta-analysis. MLB and AAR were major contributors in writing the manuscript. All authors read and approved the final manuscript.

\subsection{Acknowledgments}

Not applicable.

\section{Abbreviations}

ACEi - angiotensin converting enzyme inhibitor

ADE - adverse drug event

AHS - American Headache Society

ARB - angiotensin receptor blocker 
CCB - calcium channel blocker

CENTRAL - Cochrane Controlled Register of Trials

CHS - Canadian Headache Society

$\mathrm{Cl}$ - confidence interval

HADS - Hospital Anxiety and Depression Scale

HERDIN - Health Research and Development Information Network

HIT - Head Impact Test

ICHD - International Classification of Headache Disorders

IHS - International Headache Society

LILACS - Literatura Latino-Americana e do Caribe em Ciências da Saúde

MCS - mental component summary

MD - mean difference

MeSH - Medical Subject Headings

MIDAS - Migraine Disability Assessment

MOOSE - Meta-analysis Of Observational Studies in Epidemiology

ND - no data

NMDA - N-methyl D-aspartate

NRS - Numerical Rating Scale

PCS - physical component summary

PRISMA - Preferred Reporting Items for Systematic reviews and Meta-analyses

PSQI - Pittsburgh Sleep Quality Index

RCT - randomized controlled trial

RevMan - Review Manager

$\mathrm{RR}$ - risk ratio 
SD - standard deviation

SF-12 - Short Form 12

YLD - years lived disability

\section{References}

[1] R.J. Stark, K. Ravishankar,.C. Siow, S. Lee, R. Pepperle, S. Wang, Chronic migraine and chronic daily headache in the Asia-Pacific region: a systematic review, Cephalalgia. 33 (2012) 266-283. doi:10.1177/0333102412468677.

[2] M. Vincent, S. Wang, Headache Classification Committee of the International Headache Society (IHS) The International Classification of Headache Disorders, 3rd edition, Cephalalgia. 38 (2018) 1-211. doi:10.1177/0333102417738202.

[3] M. Linde, M. Wm, C. Ep, M. Dc, Valproate (valproic acid or sodium valproate for the prophylaxis of episodic migraine in adults, Cochrane Database Syst. Rev. (2016).

doi:10.1002/14651858.CD010608.Memantine.cochranelibrary.com.

[4] F. Bill, M.G. Foundation, Global, regional, and national burden of migraine and tension-type headache, 1990 - 2016: a systematic analysis for the Global Burden of Disease Study 2016, Lancet Neurol. 17 (2018) 954-976. doi:10.1016/S1474-4422(18)30322-3.

[5] P.J. Goadsby, P.R. Holland, M. Martins-oliveira, J. Hoffmann, C. Schankin, S. Akerman, Pathophysiology of migraine: a disorder of sensory processing clinical manifestations neural basis of migraine triggers, Physiol. Rev. 97 (2019) 553-622. doi:10.1152/physrev.00034.2015.

[6] M. Bigal, A. Rapoport, F. Sheftell, D. Tepper, Memantine in the preventive treatment of refractory migraine, Headache. 48 (2008) 1337-1342. doi:10.1111/j.1526-4610.2008.01083.x.

[7] R. Noruzzadeh, A. Modabbernia, V. Aghamollaii, M. Ghaffarpour, M. Harirchian, S. Salahi, N. Nikbakht, N. Noruzi, A. Tafakhori, Memantine for prophylactic treatment of migraine without aura- a randomized double-blind placebo-controlled study.pdf, Headache. 56 (2015) 95-103. doi:10.1111/head.12732.

[8] J.C. Rau, D. Dodick, Other Preventive Anti-Migraine Treatments: ACE Inhibitors, ARBs, Calcium Channel Blockers, Serotonin Antagonists, and NMDA Receptor Antagonists, Curr. Treat. Options Neurol. 21 (2019) 17. doi:10.1007/s11940-019-0559-0.

[9] S. Silberstein, P. Tfelt-Hansen, D.MEMANTINE. Dodick, V. Limmroth, R.B. Lipton, J. Pascual, S.J. Wang, Guidelines for controlled trials of prophylactic treatment of chronic migraine in adults, Cephalalgia. 28 (2008) 484-495. doi:10.1111/j.1468-2982.2008.01555.x. 
[10] D.F. Stroup, Meta-analysis of observational studies in epidemiology: a proposal for reporting, J. Am. Med. Assoc. 283 (2003) 2008. doi:10.1001/jama.283.15.2008.

[11] D. Moher, A. Liberati, J. Tetzlaff, D.G. Altman, T.P. Group, Preferred Reporting Items for Systematic Reviews and Meta-Analyses: The PRISMA Statement, PLoS Med. 6 (2009) e1000097. doi:10.1371/journal.pmed.1000097.

[12] Committee of the International Headache Society., Classification and diagnostic criteria for headache disorders, cranial neuralgias and facial pain, Cephalalgia. 24 (2004) 1-160.

[13] M. Murad, S. Sultan, S. Haffar, F. Bazerbachi, Methodological quality and synthesis of case series and case reports, Evid. Based. Med. 23 (2018) 60-63. doi:10.1136/bmjebm-2017-110853.

[14] A. Charles, C. Flippen, M.R. Reyes, K.C. Brennan, Memantine for prevention of migraine: a retrospective study of 60 cases, J. Headache Pain. 8 (2007) 248-250. doi:10.1007/s10194-007-0406-7.

[15] F. Assarzadegan, M. Sistanizad, Tolerability and efficacy of Memantine as add on therapy in patients with migraine, Iran. J. Pharm. Res. 16 (2017) 791-797.

[16] S. Shanmugam, K. Karunaikadal, S. Varadarajan, M. Krishnan, Memantine ameliorates migraine headache, Ann. Indian Acad. Neurol. 22 (2019) 286-290. doi:10.4103/aian.AIAN.

[17] S.D. Silberstein, S. Holland, F. Freitag, D. Dodick, C. Argoff, E. Ashman, Evidence-based guideline update: Pharmacologic treatment for episodic migraine prevention in adults, Neurology. 78 (2012) 13371345. doi:10.1212/wnl.0b013e3182535d20.

[18] M.R. Farlow, S.M. Graham, G. Alva, Memantine for the treatment of Alzheimer's disease: tolerability and safety data from clinical trials, Drug Saf. 31 (2008) 577-585. doi:10.2165/00002018-20083107000003.

[19] A. Vgontzas, R. Burch, Episodic migraine with and without aura: key differences and implications for pathophysiology, management, and assessing risks, Curr. Pain Headache Rep. 22 (2018) 28. doi:10.1007/s11916-018-0735-z.

\section{Figures}



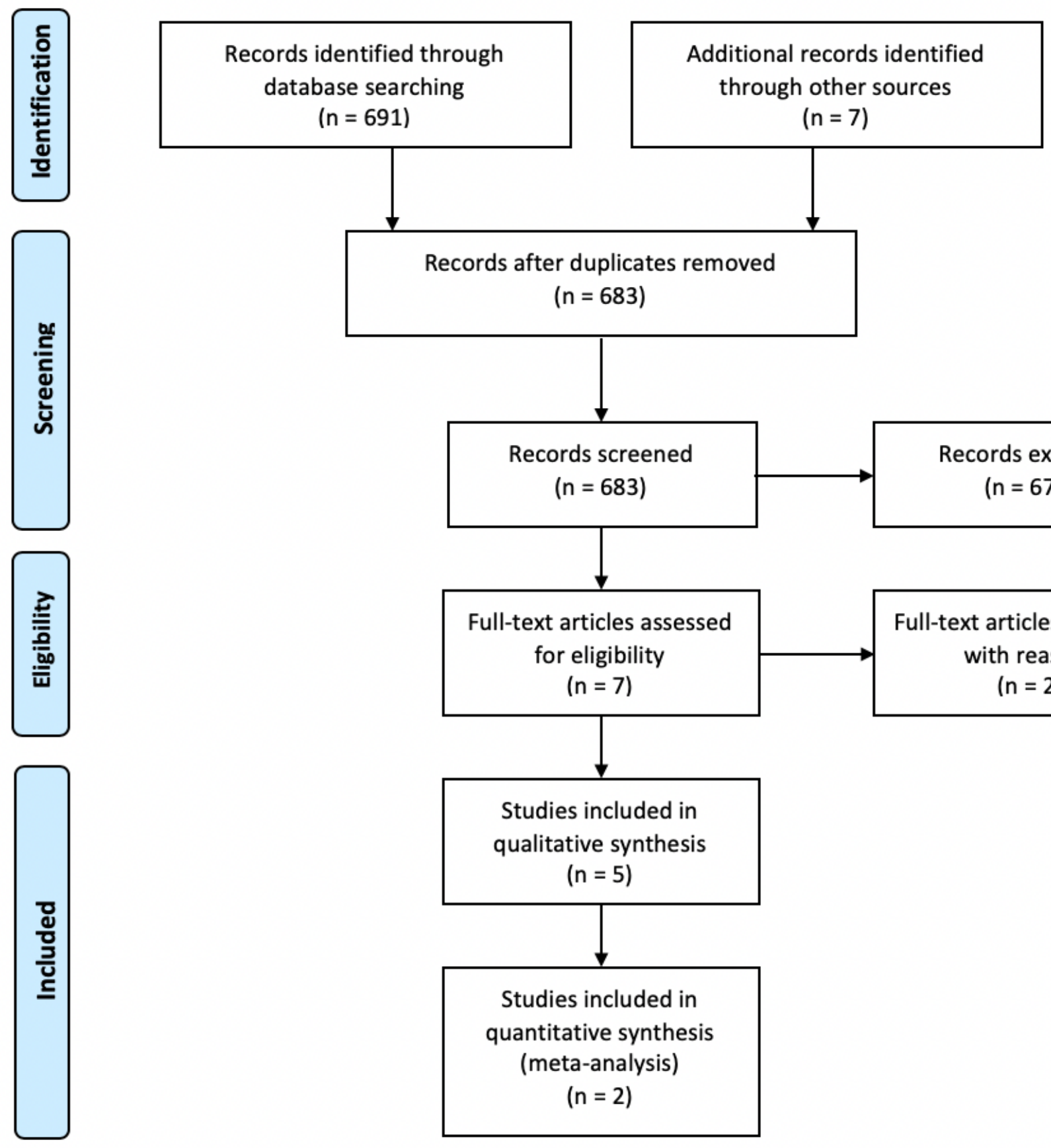

Records after duplicates removed

$$
\text { ( } n=683 \text { ) }
$$
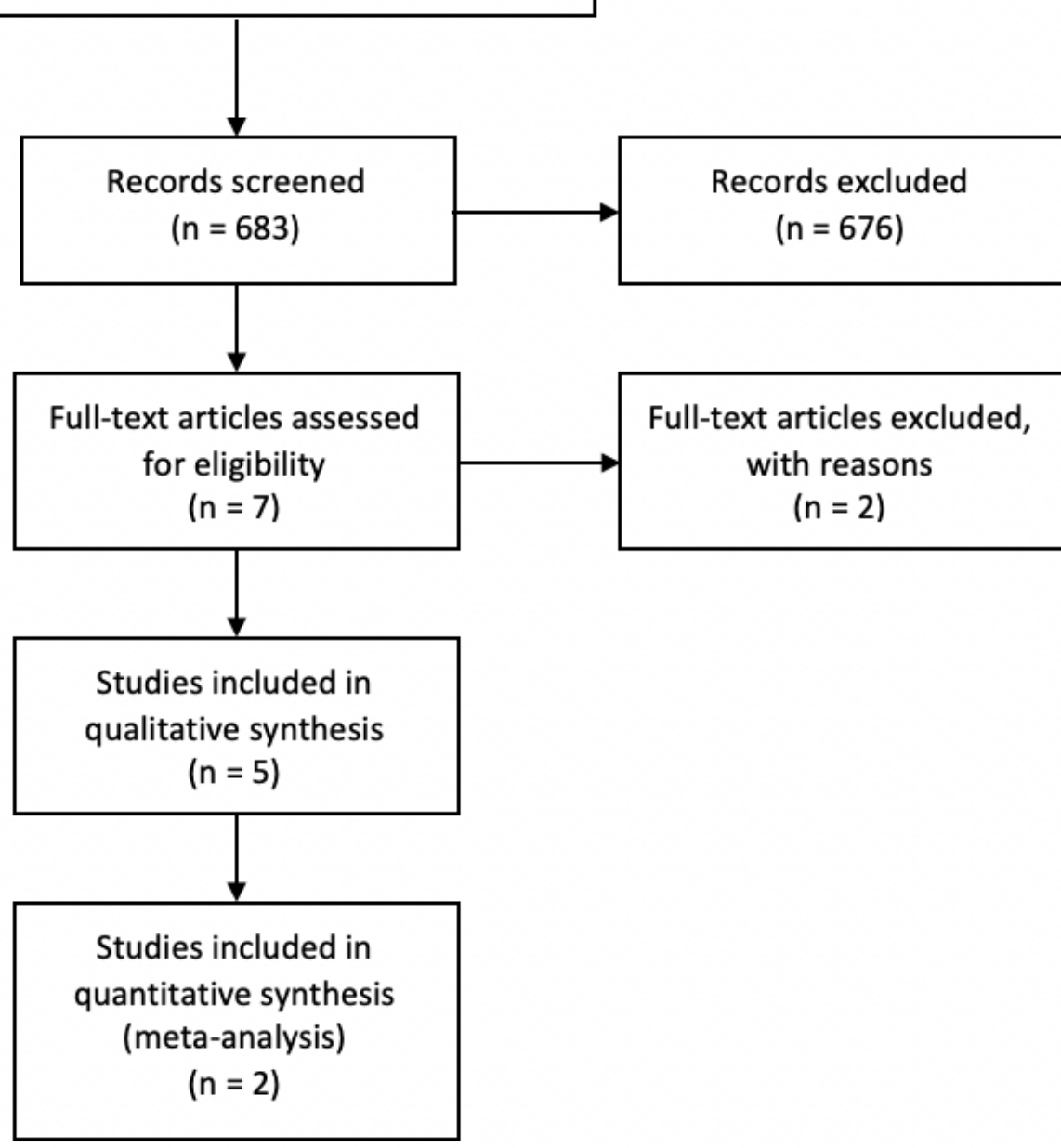

\section{Figure 2}

Flow diagram of information of the review as adapted from PRISMA guidelines [11]. 


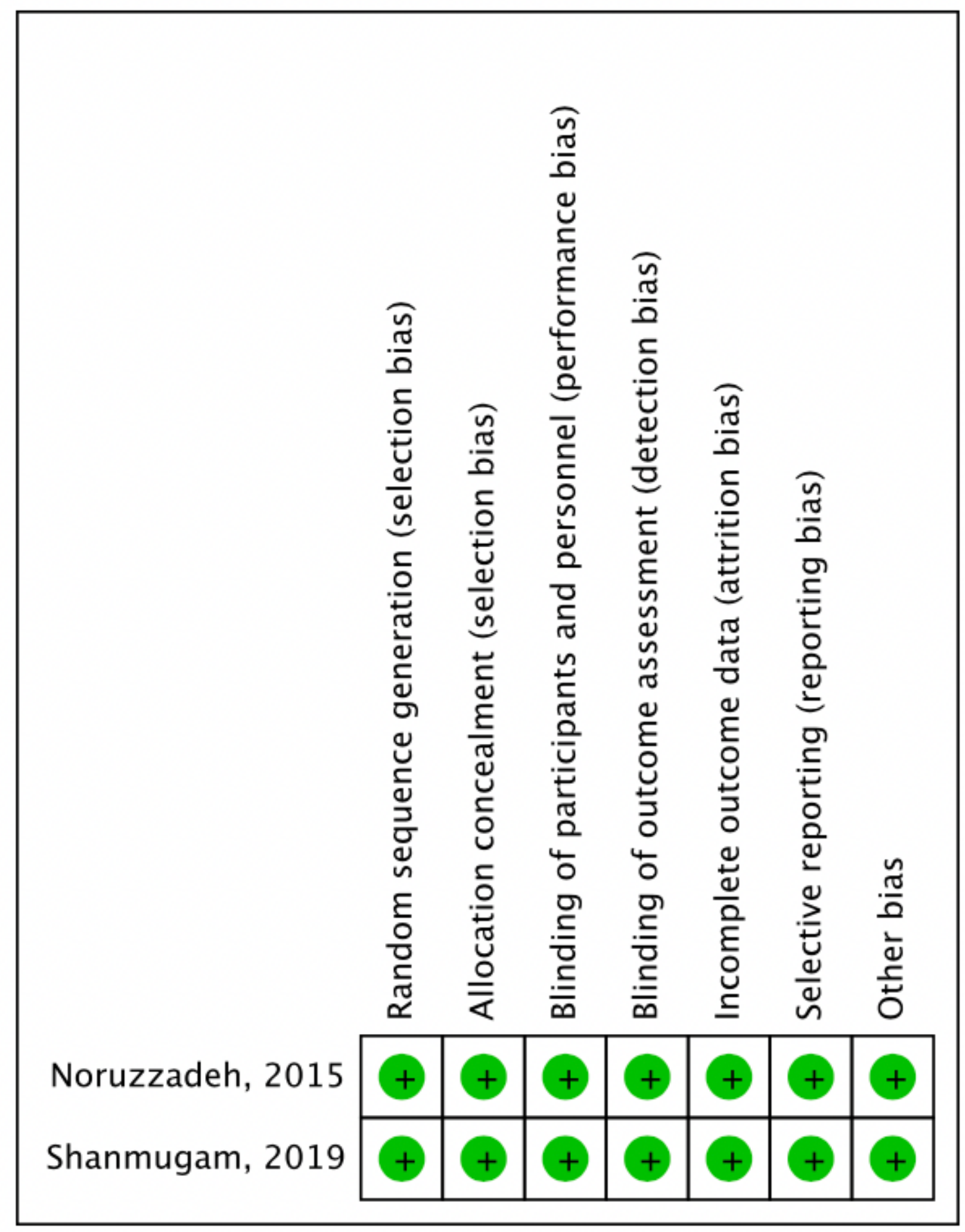

Figure 3

Risk of bias summary using the Cochrane Collaboration's tool for randomized control trials. 


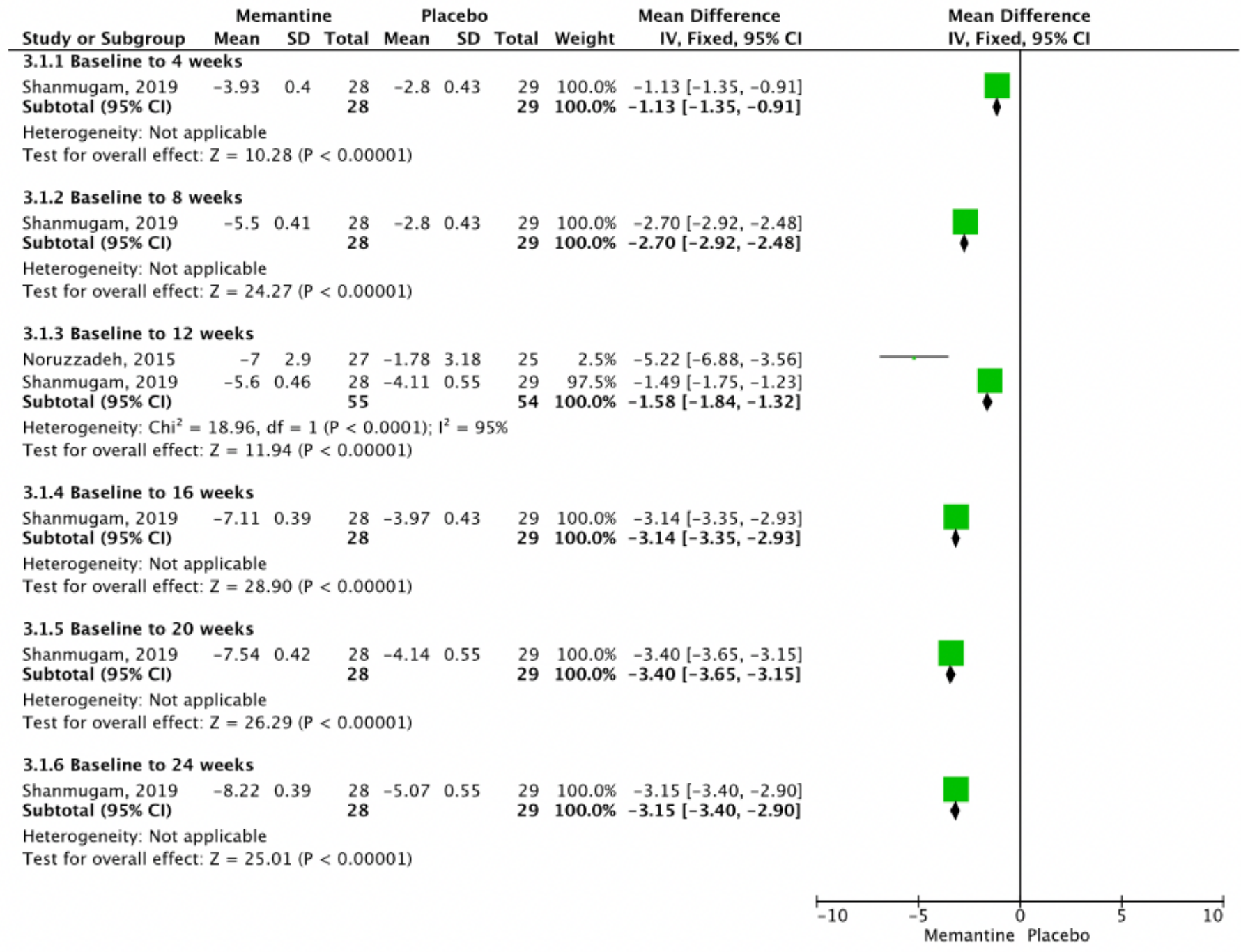

\section{Figure 5}

Forest plot comparing Memantine and placebo in terms of headache frequency in a month from baseline to various consecutive timepoints. 


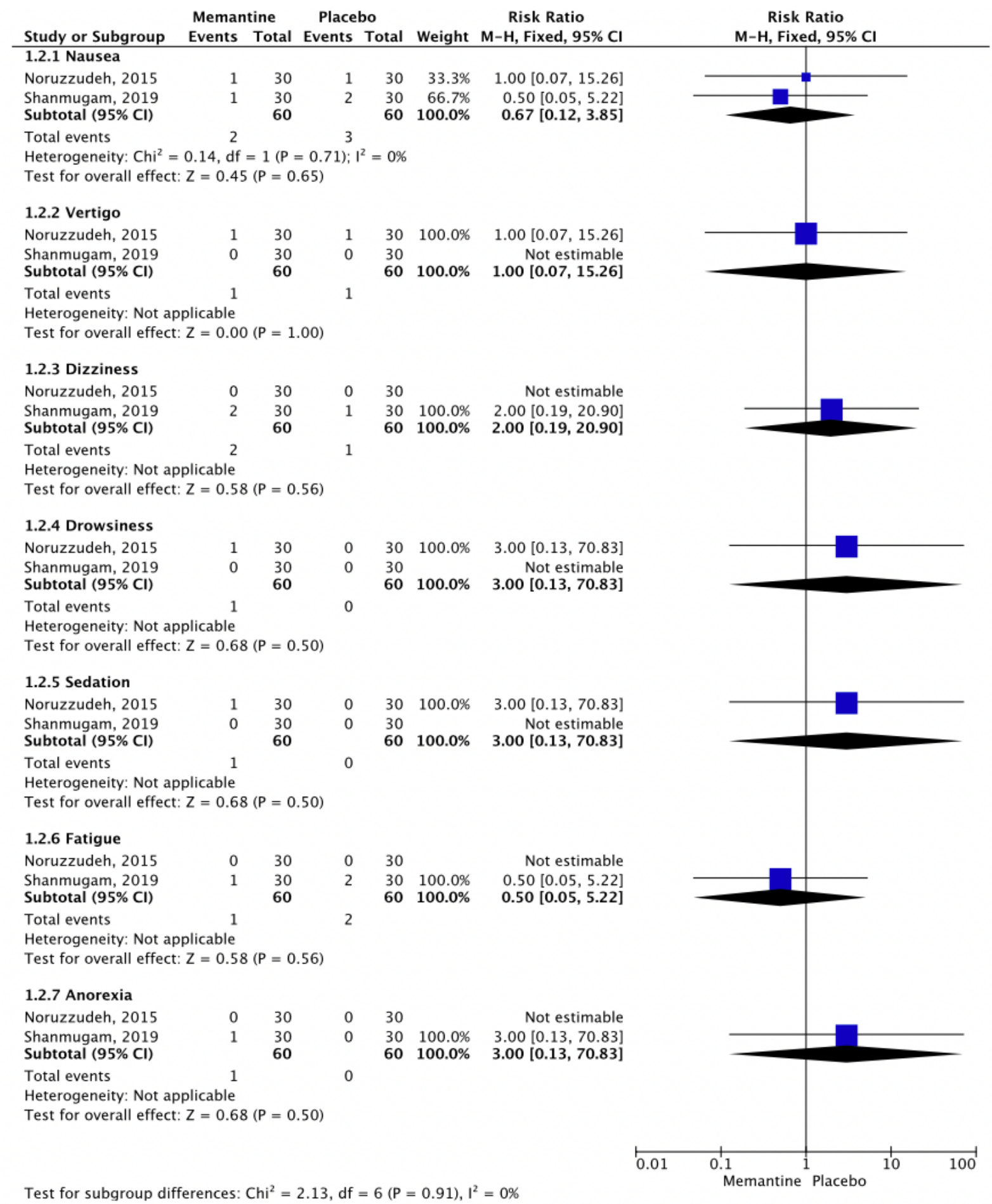

\section{Figure 8}

Forest plot of adverse drug events seen with administration of Memantine compared to placebo. 